\title{
Corrosion studies of steel rebar samples in neutral sodium chloride solution also in the presence of a bio-based (green) inhibitor
}

\author{
A.S. Abbas, ${ }^{1}$ É. Fazakas ${ }^{2}$ and T.I. Törö ${ }^{1}{ }^{*}$ \\ ${ }^{1}$ Faculty of Materials Science and Engineering, University of Miskolc, Hungary \\ ${ }^{2}$ Department of Surface Technology, Bay Zoltán Nonprofit Ltd. for Applied Research, \\ Budapest, Hungary \\ *E-mail:fektt@uni-miskolc.hu
}

\begin{abstract}
Steel rebar samples obtained from a steel mill operating in Hungary were investigated in several sets of laboratory experiments to reveal some of their corrosion properties in aqueous solutions containing sodium chloride salt. The effectiveness of an organic inhibitor extracted from a cheap organic waste of orange peel (so-called bio-based "green" inhibitor) was also studied. Results of the electrochemical polarisation measurements, as well as those of the direct corrosion weight-loss testing, showed the inhibition potential of the chosen new green inhibitor in stagnant neutral aqueous $3.5 \mathrm{wt} \% \mathrm{NaCl}$ solutions in contact with air. It makes this bio-based inhibitor a promising candidate for using it as corrosion mitigating admixture in steel reinforced concrete.
\end{abstract}

Keywords: steel rebar, green inhibitor, orange peels, corrosion properties.

Received: December 18, 2017. Published: December 31, 2017

doi: $\underline{10.17675 / 2305-6894-2018-7-1-4}$

\section{Introduction}

Corrosion of steel rebars in reinforced concrete is an electrochemical process that causes the dissolution of iron to form a range of solid products. Corrosion products is a complex mixture of iron oxides, hydroxides and hydrated oxides that evolves according to the prevailing local environment. Depending on their level of oxidation and the availability of moisture, corrosion products have specific volumes ranging from about two to six times that of the iron consumed. As such, the main damage caused by corrosion of reinforcement in concrete is not the loss of steel cross-section, but cracking of the concrete cover due to expansive stresses exerted by the continued deposition of corrosion products (mostly oxides and hydroxides) near the steel-concrete interface. This leads to progressive deterioration and even spalling of the concrete cover as in Figure 1 [1-6]. 


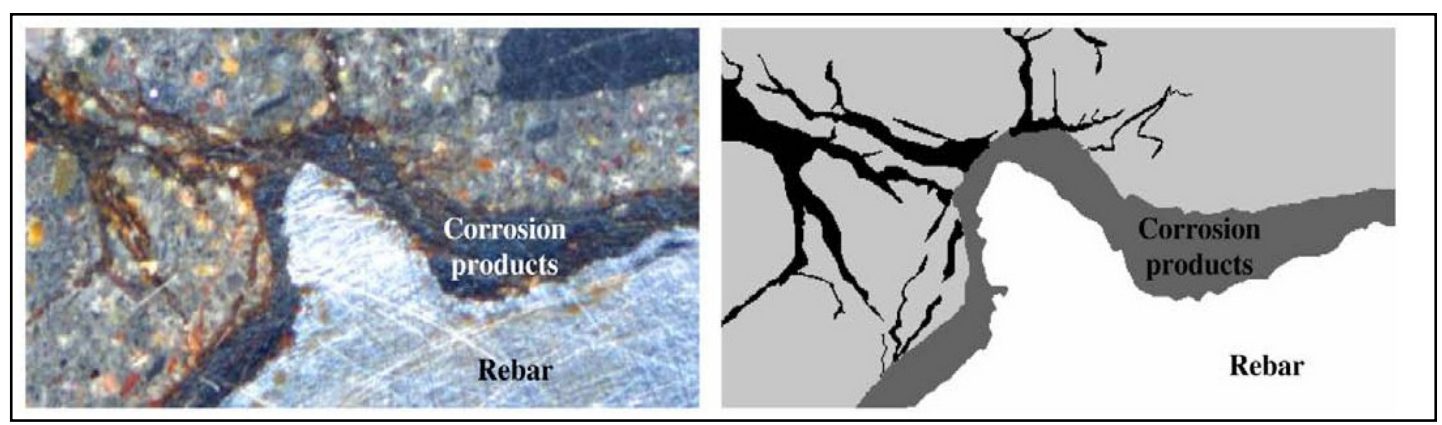

Figure 1. Magnified cross section and illustration of the accumulation of corrosion products between the steel rebar and concrete interface followed by initiation of cracks in the concrete cover [6].

Thanks to the extremely wide uses of iron base alloys worldwide, there are also quite many corrosion studies of iron alloys in different environments. Vukovic et al. [7], for example, published a recent paper on the corrosion of pure iron $(\mathrm{Fe}, 99.9 \mathrm{wt} \%$; $\mathrm{C}, 0.010$; $\mathrm{Mn}, 0.022 ; \mathrm{P}, 0.0032 ; \mathrm{Si}, 0.0028$; and $\mathrm{S}, 0.0085)$ in the presence of Thiobacillus ferrooxidans bacteria, which can also be considered as something like a bio-based constituent, and without it. In this paper they also described in details the methodology and many difficulties in the "proper" use of the linear polarisation technique (i.e. determining the open circuit potential (OCP), the Tafel slopes/constants $\left(b_{\mathrm{a}}, b_{\mathrm{c}}\right)$, and the polarization resistance $\left(R_{\mathrm{p}}\right)$. As for the magnitude of the corrosion rates of high purity iron, calculated by the Stern-Geary equation [8], they reported $R_{\mathrm{p}}$ values between about 100 to $200 \mathrm{kOhm} \cdot \mathrm{cm}^{2}$ in de-ionized water base solutions in the $\mathrm{pH}$ range of $1 \ldots 4$ adjusted with adding sulphuric acid and sodium hydroxide. These stationary values were reached after 24 hours with the exception at $\mathrm{pH}=4$, where a much longer ( $>72$ hours) conditioning time elapsed before reaching a stable $R_{\mathrm{p}}$ value. Then the corrosion rates could also be estimated taking the $B$ constant of $50 \mathrm{mV}$ (assuming that $b_{\mathrm{a}}=b_{\mathrm{c}}=100 \mathrm{mV}$ ), in the Stern-Geary equation:

$$
I_{\text {corr }}=\left(1 / 2.3 R_{\mathrm{p}}\right)\left(b_{\mathrm{a}} b_{\mathrm{c}} /\left(b_{\mathrm{a}}+b_{\mathrm{c}}\right)\right)=\left(1 / 2.3 R_{\mathrm{p}}\right) B \text {. }
$$

Based on the above evaluation Vukovic et al. [7] reported $I_{\text {corr }}$ rates in the range between 100 and $250 \mathrm{nA} \cdot \mathrm{cm}^{-2}$ in the given slightly acidic aqueous solutions in contact with air.

Also recently, El-Sayed M. Sherif [9] studied the corrosion rates of pure iron in neutral chloride solution with and without an organic inhibitor, 1,1'-thiocarbonyldiimidazole. In principle using the same electrochemical method on pure iron electrode immersed for $1 \mathrm{~h}$ (conditioning time) in freely aerated $3.5 \mathrm{wt} \% \mathrm{NaCl}$ solution ( $\mathrm{pH}$ close to neutral), the reported corrosion rate for the not-inhibited case was $15 \mu \mathrm{A} \cdot \mathrm{cm}^{-2}$, which is higher than the ones mentioned above. Anyhow, the above cited corrosion rates correspond to mass losses expressed in decrease in thickness around and below $0.1 \mathrm{~mm} / \mathrm{annum}$. (The conversion used here is that $1 \mu \mathrm{A} / \mathrm{cm}^{2}=11.6 \mu \mathrm{m} / \mathrm{a}$ for the uniform corrosion of pure iron). It also means that the so-called general (and uniform) corrosion rates of iron in such only 
slightly aggressive aqueous environments in contact with air are relatively low, but not at all negligible, especially when facilities like the steel reinforced concrete structures expected life time might reach, in some cases, even over hundred years. Therefore, on the long run, the risk of corrosion of reinforcing steel in concrete is indeed an important issue even if at the beginning the steel rebars surface is mostly in passive state, i.e. covered with a thin oxide layer, which for a while can hinder the faster progress of the steel's corrosion, especially under chemically less agressive alkaline conditions.

Taking into consideration also these corrosion rate modifying initial circumstances, our laboratory experiments were designed with both surface conditions, namely, that of the as-received oxide covered state and also with the active state after removing any surface coverage, like the mill scale oxides, which is the most common initial state of the reinforcing steel rebars being used in concrete structures. Consequently, the main purpose of this study was to perform experimental laboratory research to reveal the major corrosion related properties of some steel rebar samples having different initial surface conditions and so immersed in sodium chloride solutions open to air, as similar situations might also arise during the service life of steel reinforced concrete structures, for example, close to the sea or where chloride salts are still used for de-icing roads and bridges.

\section{Experimental}

The steel rebar samples were obtained from a secondary steel making factory (Ózd Steelworks Ltd.), which produces different hot rolled rod and wire products. The hot rolled and ribbed reinforcing steel bar samples diameter was about $8 \mathrm{~mm}$. The steel quality was in compliance with the standards EN 10080 [10] and the steel samples contained about 0.2 wt. $\% \mathrm{C}$, somewhat over $1 \% \mathrm{Mn}$, and about $0.3 \% \mathrm{Si}$ as the main alloying elements. The as-received samples surface was covered with a thin layer of mill scale (iron oxide). For some experiments, it was removed either by some proper mechanical or chemical means in order to get a clean and fresh ('active') surface condition. However, part of the corrosion studies (weight-loss measurements) were also performed with steel rebar samples having both of the as-received and acid pickled initial surface conditions.

The as-received surface condition of the steel rebar samples were also characterized by scanning electron microscopy (SEM) coupled with energy-dispersive X-ray spectroscopic micro-analyser (EDS). The acid pickling sample preparation step was done in hydrochloric acid to fully remove the surface mill scale from the ribbed surface of the steel rods.

The corrosion resistances of the steel samples were first evaluated by the linear polarization corrosion testing method. The potentiodynamic polarization measurements were carried out in a typical three-electrode electrochemical cell setup with the specimen as the working electrode (samples), saturated calomel $\left(\mathrm{Hg} / \mathrm{Hg}_{2} \mathrm{Cl}_{2} / \mathrm{KCl}\right)$ reference electrode and a platinum $(\mathrm{Pt})$ counter electrode. The potential of the working electrode was measured through the Luggin probe with respect to the reference electrode which was placed as close as possible to the specimen. The electrochemical polarization curves were measured in the 
tested electrolyte solutions at $25^{\circ} \mathrm{C}$ using a Zahner potentiostat. Electrochemical characteristic parameters, such as electrochemical corrosion potential $\left(E_{\text {corr }}\right)$, corrosion current density $\left(i_{\text {corr }}\right)$ can be obtained by evaluating the polarization curves. For the electrochemical polarization measurements, the steel rebar samples surface $\left(\sim 0.5 \mathrm{~cm}^{2}\right)$ were first wet polished with 400, 600, 800, 1200, 2400 grade silicon carbide paper followed by $1 \mu \mathrm{m}$ diamond paste mounted on a metallographic lapping machine then immersed in the electrolyte solution.

Before commencing the polarisation measurements the (steady-state) corrosion potential was recorded referenced to a saturated calomel electrode (SCE), then the electrode potential was scanned with a constant rate of $10 \mathrm{mV} / \mathrm{min}$ "down" to more negative (i.e. so-called cathodic) polarisation potentials. This procedure was then repeated in the same manner after longer periods of immersion times of 1, 3, 5, 7, and 24 hours (Table 1).

Table 1. Experimental conditions of the electrolyte solutions during the electrochemical corrosion polarization measurements.

Aqueous electrolyte

Composition / Conditions

\section{Parameters}

\begin{tabular}{ccc}
\hline Dissolved NaCl, wt.\% & 3.5 & 3.5 \\
\hline $\begin{array}{c}\text { Inhibitor (orange peel extract } \\
\text { stock suspension) }\end{array}$ & NO & $\sim 10$ wt.\% \\
\hline $\begin{array}{c}\text { Dissolved air } \\
\text { of rebar, h }\end{array}$ & $\begin{array}{c}\text { Through solution-air interface } \\
\text { (No mixing) }\end{array}$ & $\begin{array}{c}\text { Through solution-air interface } \\
\text { (No mixing) }\end{array}$ \\
\hline $\begin{array}{c}\text { Immersion times (conditioning) } \\
\text { pH and temperature }\end{array}$ & $\begin{array}{c}\text { Neutral (pH 7) solution at } \\
\text { room temperature }\end{array}$ & $\begin{array}{c}\text { Neutral (pH } \sim 7,3,5,24 \\
\text { room temperature }\end{array}$
\end{tabular}

In another set of experiments the weight loss of steel rebars having lengths of around $10 \mathrm{~cm}$ were also measured before and after immersion in $\mathrm{NaCl}$ solutions in air. The test solutions $\mathrm{NaCl}$ content was the same as given in Table 1, but the concentrations of the inhibitor suspension was reduced to $1 \%$ and $3 \%$, respectively.

The inhibitor tested in these experiments was a methanol extract of fine ground dry orange peel. The Soxhlet-extraction was made for 6 hours, then the methanol was evaporated under reduced pressure $(60 \mathrm{mbar})$ at $40^{\circ} \mathrm{C}$ and the extract was dispersed/ dissolved in distilled water. This aqueous suspension of the orange peel extract was then used as a bio-based inhibitor stock solution/suspension and was added in different percentages to the corrosion test electrolyte solutions of $\mathrm{NaCl}$ (See also in Table 1). 
In an additional set of experiment the as-received and acid pickled rebar samples were immersed in stagnant $3.5 \% \mathrm{NaCl}$ solutions with and without inhibitor and open to air at room temperature for several weeks in order to check the progress of corrosion under somewhat more realistic conditions compared to that of the polarisation experiments. Time to time the steel samples were removed from the solutions, washed first in running water then distilled water and wiped off with a blotting paper before measuring the weights.

\section{Results}

\section{Initial surface condition of the steel rebars}

The as-received steel rebar sample's surface is covered by a thin layer of oxide (mill scale), which was further characterized by using the SEM EDS technique (Figure 2).

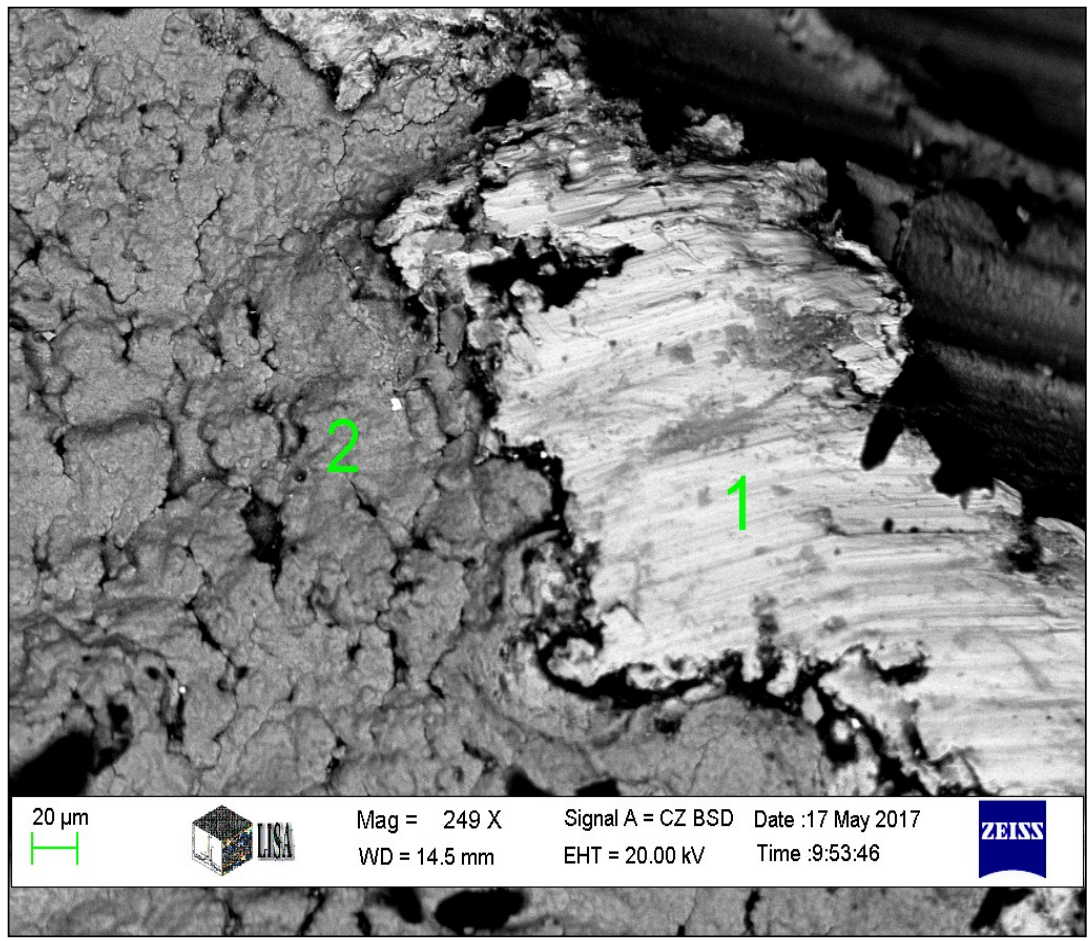

Figure 2. SEM image with the points where EDS analysis was also made on the mill scale covered rebar sample. At point 1: $\mathrm{Fe} \sim 51$ at.\%, $\mathrm{O} \sim 41$ at.\%; while at point 2: $\mathrm{Fe} \sim 49$ at.\%, $\mathrm{O} \sim 51$ at.\%.

It is clearly seen in Figure 2 that the mill scale covered surface of the rebar sample is rather rough with many cracks and other surface defects. Its average thickness is around $1 \mu \mathrm{m}$.

Such a surface scale could be relatively easily removed by mechanical brushing or chemically dissolving in pickling acid of $\mathrm{HCl}(\sim 10 \mathrm{wt} \%)$. 


\section{Electrochemical polarisation measurements}

By means of this technique it was intended to reveal any difference in the chemical surface activity of the steel rebar sample put in $\mathrm{NaCl}$ solution compared with the case when the given electrolyte solution contained also a relatively large amount $(\sim 10 \%$ admixture $)$ of the inhibitor stock suspension. For these two cases the recorded polarisation curves are shown in Figure 3 a) and b).
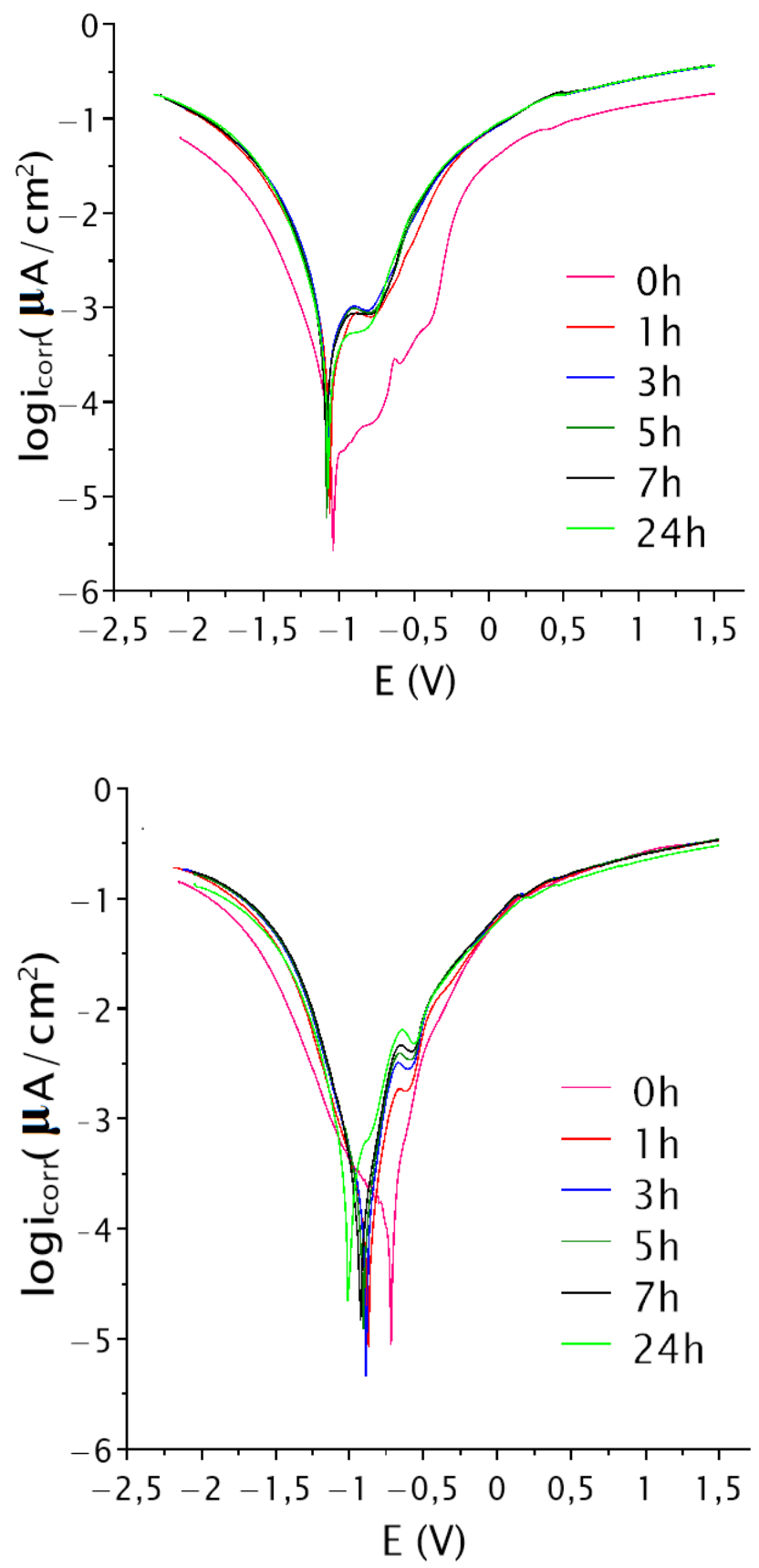

Figure 3. Polarisation curves recorded in pure sodium chloride (3.5\%) solution in air with no inhibitor (a), and also with inhibitor of orange peel extract (b). Polarisation potentials refer to that of the saturated calomel electrode. 
The open circuit potentials (OCP) relatively quickly stabilized in case (a), while they were shifting to more negative values even after several hours in the case when the $\mathrm{NaCl}$ solution contained the bio-based inhibitor admixture as well. For this latter case this phenomenon can be interpreted as an indication of the changing and time dependent electrode surface activity. For the two cases, otherwise, also the corrosion rates could have been calculated from the measured polarisation curves, based on the approximation described in short in the introduction, but eventually it was decided to use a much less indirect method, namely measuring the weight losses of the steel samples immersed in the same $\mathrm{NaCl}$ solutions containing now considerably less amounts (only 1 and 3\%) of the inhibitor stock solution. In this way a "closer to reality" situation as well could be tested.

\section{Weight loss measurements}

In order to be able to follow the progress of corrosion we used the technique of weight-loss measurements also on real rebar specimens having two different surface conditions (Asreceived / Treated with Acid Pickling) immersed in three different media $(3.5 \% \mathrm{NaCl}$ solution $/ 3.5 \% \mathrm{NaCl}+1 \%$ green inhibitor solution / and $3.5 \% \mathrm{NaCl}+3 \%$ green inhibitor solution). Three rebar samples were used for each setup and first were tested every day (24 h) then once a week.

By dividing the mass loss differences with the time periods elapsed between two consecutive weighing measurements, the rate of corrosion could also be approximated.

\section{Discussion}

\section{Short Characterization of the orange peel bio-based admixture /inhibitor/}

In addition to the use of synthetic chemicals as corrosion inhibitors, for some years there is also a new trend of testing and using so-called "green" inhibitors [11] which are mostly produced from cheap organic wastes. Our choice as the source of obtaining a green corrosion inhibitor to be used later in steel reinforced concrete systems was the orange peel which is accumulated, for example, as an organic waste in the production of orange juice. Orange peel consists of several chemical constituents like organic fats, pectins, lignin, reducing and non-reducing sugars all of which have many active functional groups (carboxyl, hydroxyl, aldehyde, etc.) which make it a good candidate to show surface modifying properties if its soluble components are properly extracted from it and used afterwards as an adsorptive type bio-based inhibitor.

\section{Discussion on the measured polarisation curves}

At the open circuit potentials (OCP) the overall rate of partial oxidation reaction(s) are equal to those of the reduction reactions. In this close to neutral salt solution open to air, the most probable cathodic (reduction) reaction is the reduction of dissolved air, i.e.: 


$$
1 / 2 \mathrm{O}_{2}(\mathrm{aq})+\mathrm{H}_{2} \mathrm{O}+2 \mathrm{e}^{-} \rightarrow 2 \mathrm{OH}^{-}(\mathrm{aq})
$$

which reaction consumes the electrons of the anodic (corrosion) reaction of iron dissolution:

$$
\mathrm{Fe}(\mathrm{s}) \rightarrow \mathrm{Fe}^{2+}(\mathrm{aq})+2 \mathrm{e}^{-}
$$

Then the surface formed water soluble ions of $\mathrm{Fe}^{2+}(\mathrm{aq})$ and $\mathrm{OH}^{-}(\mathrm{aq})$ can form also some solid hydroxide precipitates on the surface of the iron electrode (actually low alloyed carbon steel in our case) in such almost neutral aqueous solution, which solid reaction product(s) will then somewhat hinder the diffusion of these ions away from the electrode/solution interface into the bulk of the electrolyte solution. The small plateau/shoulder on the anodic polarisation curve at a few hundred $\mathrm{mV}$ more positive potentials of the OPC can be explained by such intermediate partial surface passivation with somewhat decreased anodic current densities (Figure 3a). When the $\mathrm{NaCl}$ solution contained inhibitors as well (Figure 3b) such plateaus still appear, but at somewhat higher current densities indicating the evolution of the inhibitor modified new surface conditions. Although these qualitative observations show some marked differences between the two experimental conditions, but it is rather difficult to calculate exact corrosion rates based on the Stern-Geary equation cited in the introduction as the activation polarization model does not seem to fit well to the recorded curves not showing long enough (through one or two decades of $\lg i_{\text {corr }}$ ) straight sections (so-called Tafel slopes) on the semi-logarithmic graphs. However, the approximate $i_{\text {corr }}$ values calculated from the Stern-Geary equation gave the same magnitude for the rate of corrosion as it was determined from the direct weight-loss measurements discussed below.

\section{Discussion on the weight-loss measurements}

As it is seen in Figure 4, except the case when the $\mathrm{NaCl}$ solution contained 3\% inhibitor, all the steel rebar samples started corroding twice or even three times faster than after being kept in the test solutions for several days in contact with open air. It means that with time all the samples corrosion rates decreased down to the range of about $5 \ldots 35 \cdot 10^{-5} \mathrm{~g} / \mathrm{cm}^{2} \cdot$ day, which is equivalent to around $0.1 \mathrm{~mm} /$ year dissolution and conversion rate of iron to corrosion products. Nevertheless, the lowest rate of $\sim 5 \cdot 10^{-5}$ $\mathrm{g} / \mathrm{cm}^{2} \cdot$ day observed with $3 \%$ inhibitor corresponds to a corrosion rate of only about 0.02 $\mathrm{mm} /$ year, which is a considerably slower rate than those measured without or with only $1 \%$ inhibitor. 


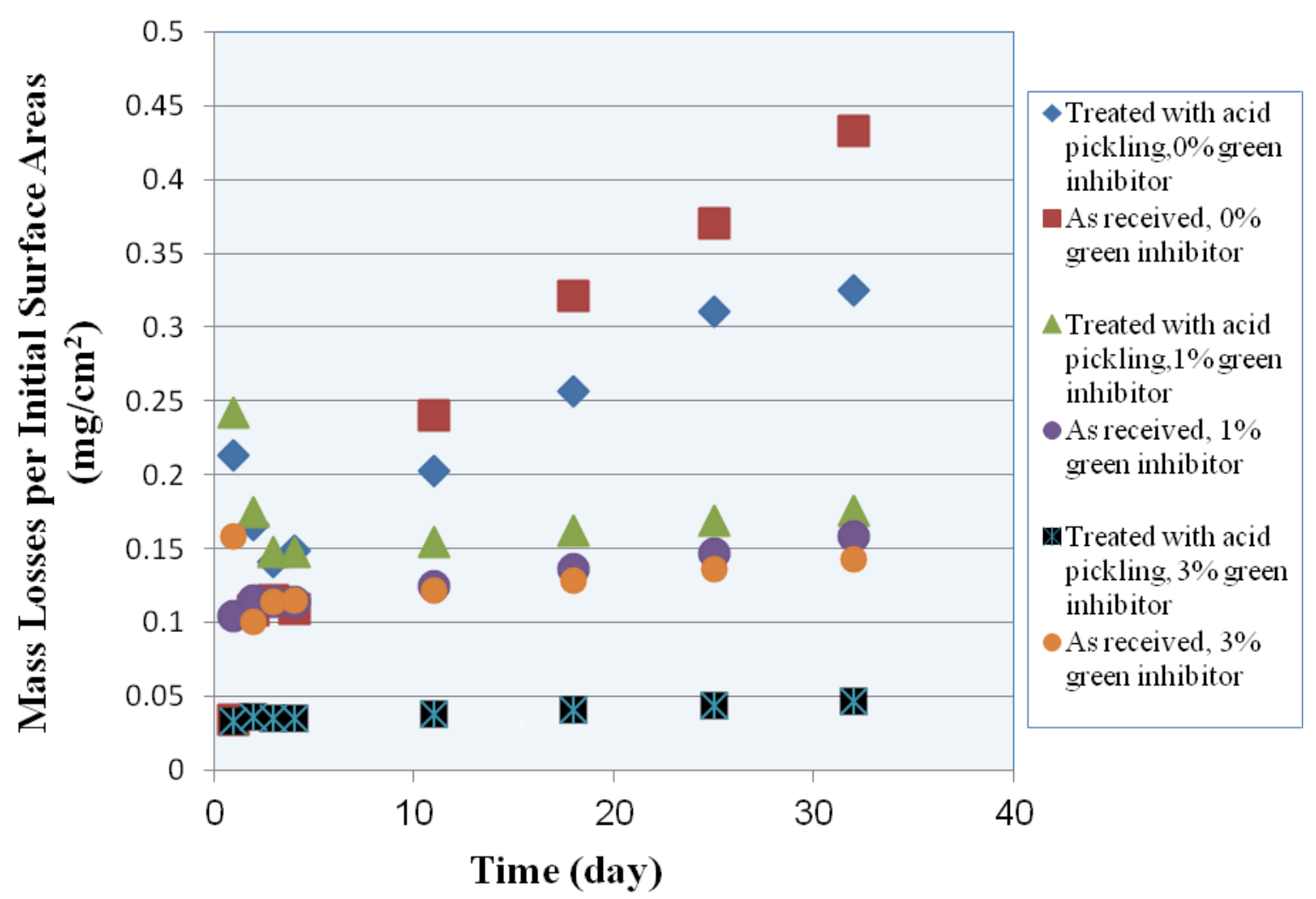

Figure 4. Mass losses per initial surface areas of the steel samples immersed in stagnant $\mathrm{NaCl}$ solutions in contact with air. The steel rebar specimens initial surface conditon (i.e. as received or acid pickled) as well as the test solutions inhibitor contents are given in the inset.

\section{Conclusion}

During our laboratory experiments (electrochemical polarisation measurements and weight loss method) the tested orange peel extract has shown promising positive effect on inhibiting the corrosion of iron in close to neutral aqueous $\mathrm{NaCl}$ solutions in contact with air. In the concentration range of the given bio-based inhibitor of 3\% seem to have decreased the rate of iron dissolution quite considerably and such amount of an organic admixture can be used in most of steel reinforced concretes. Therefore, in the future the new orange peel extract bio-based inhibitor will also be tested as an admixture of freshly prepared concrete laboratory specimens reinforced with steel rebars in order to explore its potential future applicability for the building and construction industries.

\section{Acknowledgements}

We would like to thank everyone who helped us to complete this research including technicians working with Dr. Éva Fazakas head of department of Surface Technology, Engineering Division in Budapest at the Bay Zoltán Nonprofit Ltd. as well as those belonging to the extraction laboratory of Wanhua-BorsodChem Co. in Kazincbarcika. 
We should not forget the efforts of the colleagues at the Institute of Metallurgy, University of Miskolc in providing all the possibilities available to us in order to make the research successful.

\section{References}

1. D. Talbot and J. Talbot, Corrosion Science and Technology, CRC Press, London, 1998.

2. A. Bentur, S. Diamond and N.S. Berke, Steel Corrosion in Concrete, Fundamentals and Civil Engineering Practice, Taylor \& Francis, 1997.

3. L. Bertolini, B. Elsener, P. Pedeferri and R. Polder, Corrosion of Steel in Concrete, Wiley, 2004.

4. ACI Committee 222, Protection of metals in concrete against corrosion, ACI 222R-01, ACI Manual of Concrete Practice, 2005.

5. J.P. Broomfield, Corrosion of steel in concrete, understanding, investigation and repair, Second ed., Taylor \& Francis, London, 2007.

6. H.S. Wong, A.R. Karimi, N.R. Buenfeld, Y.X. Zhao and W.L. Jin, Microstructure of corroded steel-concrete interface, on the Web:

http://www.imperial.ac.uk/structural-engineering/research/structuralmaterials/microstructure/

7. M. Vuković, B. Pesic, N. Štrbac, I. Mihajlović and M. Sokić, Int. J. Electrochem. Sci., 2012, no. 7, 2487.

8. M. Stern and A.L. Geary, J. Electrochem. Soc., 1957, 104, no. 1, 56.

9. M. El-Sayed Sherif, J. Electrochem. Soc., 2011, no. 6, 3077.

10. EN 10080; Steel for the Reinforcement of Concrete, European Commission mandate, 23 December, 2005.

11. M. Sangeetha, S. Rajendran, T.S. Muthumegala and A. Krishnaveni, "Green Corrosion Inhibitors - An Overview", Zaštita Materijala, 2011, 52, no. 1, 3. 